\title{
Uma tendência comum, casas diferentes: devolução na Itália, Espanha e Reino Unido
}

Paolo Fedele e Edoardo Ongaro*

Texto publicado originalmente na edição de abril de 2008 da revista Public Money \& Management

\section{Introdução}

Nas últimas duas décadas, a devolução ${ }^{1}$ tem estado em alta nas agendas de muitos governos. Devolução pode ser definida como a transferência de autoridade para organizações externas, legalmente estabelecidas, administradas por representantes eleitos (POLLITT et al., 1998). A devolução ocorre normalmente das camadas superiores para as inferiores do governo. Este artigo concentrase na devolução de governos centrais a regionais.

Reformas de devolução são processos complexos, desdobrando-se de formas diferentes e produzindo efeitos diversificados em cada país. Os processos de produção de políticas públicas que marcam a devolução no topo da agenda de um governo nacional e levam à sua promulgação podem ser extremamente diversificados. Os problemas que a devolução deve abordar variam consideravelmente e os modelos que diferentes países considerarão também podem ser 
muito diversos. No entanto, independentemente dos conteúdos específicos do pacote de reforma, de certa forma a devolução parece ser afetada por algumas características básicas de cada sistema político-administrativo, bem como pelo status da reforma da administração pública. A questão de pesquisa que este artigo aborda é: quais características do sistema político-administrativo e quais componentes da reforma da administração pública afetam a dinâmica dos processos de devolução?

O artigo compara os processos de devolução que ocorreram em dois países do Mediterrâneo (Itália e Espanha) e a experiência de devolução no Reino Unido, com menção à Escócia. O artigo destaca lições que são relevantes para uma audiência acadêmica, bem como para profissionais.

\section{Estrutura de análise e metodologia}

Um problema com os estudos comparativos é definir quais características selecionar para a comparação de acordo com os resultados a serem explicados. Como ponto de partida, esboçamos uma estrutura de referência genérica dos fatores potencialmente influentes num processo de devolução (ver figura 1), baseando-se numa extensa revisão da literatura acadêmica. Primeiro, as reformas de devolução são afetadas por características culturais, funcionais e estruturais do sistema público (Kickert, 1997; Olsen e Peters, 1996; Pollitt e Bouckaert, 2004). Tais características podem ser referidas como "contexto político-administrativo”. Embora obviamente variáveis, como qualquer outro aspecto do sistema público, tais características mudam apenas gradualmente ou com pouca freqüência ao longo do tempo.
Em segundo lugar, as regras e rotinas que restringem a forma como recursos financeiros, humanos, materiais e informacionais podem ser adquiridos e utilizados por gestores públicos afetam significativamente o processo de execução (a política de administração pública de um país, ver BARZELAY, 2001). Normas e rotinas em duas áreas - de pessoal e de auditoria e avaliação - são especialmente relevantes para a implementação da devolução.

É também importante delinear os efeitos das reformas da administração pública sobre cada sistema de gestão das entidades públicas individuais envolvidas no processo de devolução. Mesmo uma transferência de funções e competências bem concebidas para o nível regional dificilmente será plenamente introduzida se organizações regionais do setor público não forem capazes de atuar num nível de eficácia e eficiência "suficientes" (Borgonovi, 2005).

Em quarto lugar, as características do(s) setor(es) da política em que a devolução ocorre afetam a dinâmica do processo. Como argumentado por Pollitt et al. (1998), aspectos relacionados à natureza dos serviços prestados podem favorecer ou prejudicar a descentralização.

Em quinto lugar, as diferenças podem surgir a partir das características da localidade onde a devolução ocorre. Uma quantidade de fatores regionais que afetam a dinâmica da devolução foi identificada (por exemplo, Heller, 2002; Keating, 2001; PollitT et al., 1998; e num nível diferente de análise, Putnam, 1993).

O objetivo de nosso estudo de devolução na Itália, na Espanha e no Reino Unido foi investigar se e como um subconjunto desses fatores - aqueles relacionados ao contexto político-administrativo, às reformas 
de administração pública e aos efeitos sobre as organizações individuais do setor público, ou seja, os fatores em nível nacional que são objeto de estudos comparativos - afetam os processos de devolução. A análise deve ser de alguma forma "livre" de outros fatores, razão pela qual a nossa análise foca-se em episódios de nível macro de devolução que envolveram uma pluralidade de setores de políticas públicas e os efeitos são estimados em termos de valores "médios" no país como um todo. Além disso, a implantação da devolução é profundamente afetada pelo processo mais amplo de implementação de políticas públicas (KIngdon, 1994). Finalmente, o processo de devolução é profundamente afetado pelo conteúdo da reforma em si - o "pacote de reformas" (o que é descentralizado) - bem como pela forma como o processo de execução é implementado (PollitT e Bouckaert, 2004, pp. 93-96).

A análise combina duas estratégias principais de investigação social comparativa: abordagens dos "sistemas mais similares" e dos "sistemas mais diferentes” (PETERs, 1998). A escolha levou à seleção dos casos. Na Itália e Espanha, o sistema público é caracterizado pela tradição administrativa napoleônica e uma cultura administrativa Rechtsstaat (Estado de Direito); o sistema do Reino Unido é baseado na cultura administrativa do interesse público (ONGARO, 2007).

Os fatores político-administrativos representam, em sentido amplo, as variáveis independentes. As variáveis dependentes ("a dinâmica da devolução") abordam sua intensidade, ou seja, a velocidade e viabilidade do processo de reforma. $\mathrm{Na}$ Espanha, o processo tem sido relativamente intenso, enquanto no Reino Unido, pelo menos comparativamente, o processo tem sido muito intenso.

O segundo efeito analisado é um "resultado" da reforma: o nível de participação e accountability no setor público após a devolução. O foco não está na accountability "na democracia" e participação política, mas nas práticas que podem aumentar a transparência e comunicação externa, como a adoção de certidões de cidadãos, relatórios

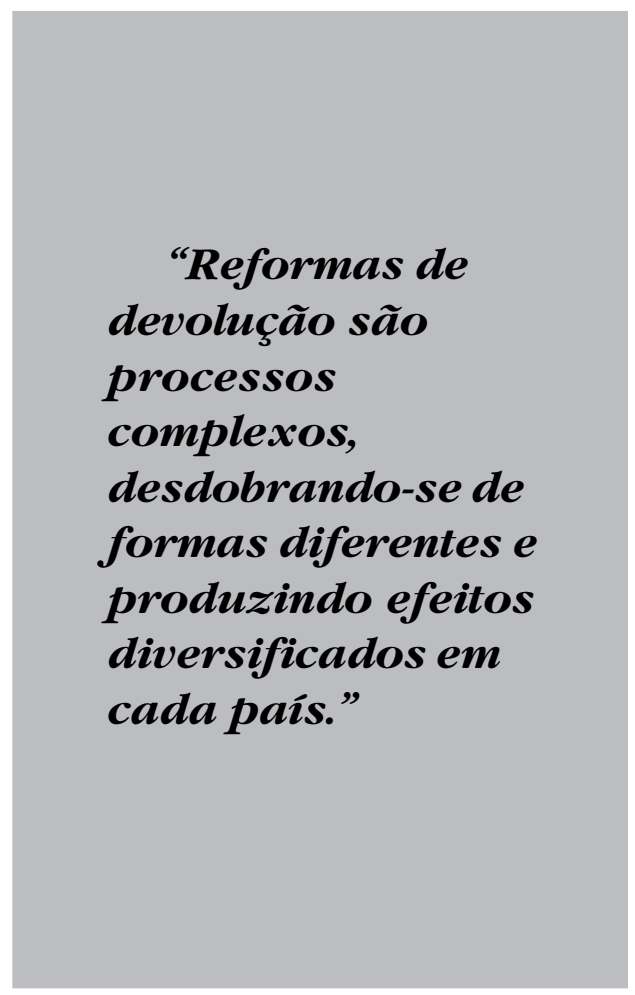

sociais, a acessibilidade de informações sobre serviços prestados e resultados obtidos. É de se observar que, na Escócia, foi relatado um aumento do nível de transparência e accountability após a devolução (EZZAmEL et al., 2004), enquanto que regiões espanholas e italianas não alteraram significativamente as rotinas administrativas no sentido de obterem mais accountability (Longo, 2001). 
Figura 1: Quadro para a análise dos processos de devolução

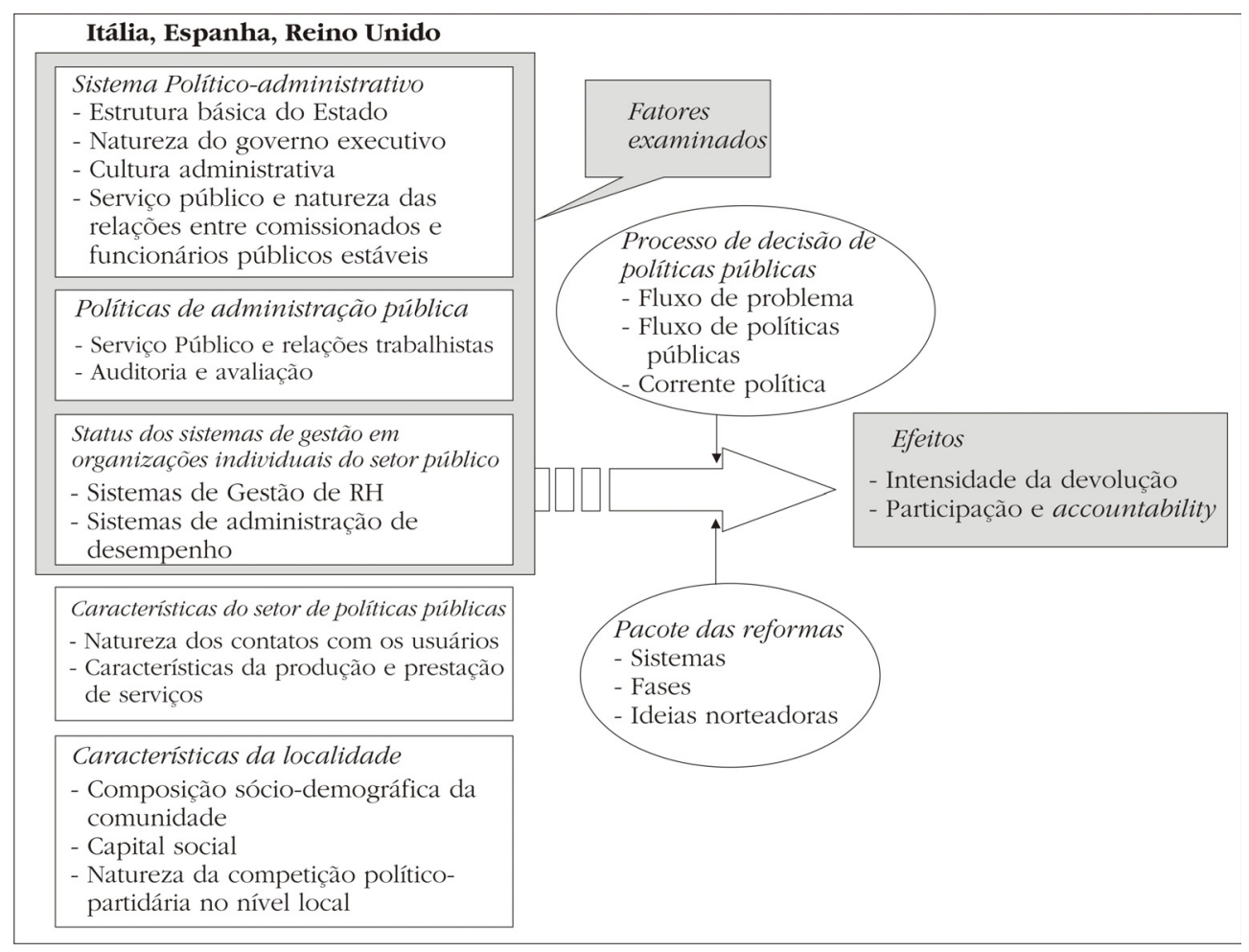

\section{O modelo comparativo: fatores político-administrativos que afetam a devolução}

Nosso modelo comparativo foi baseado numa revisão seletiva da literatura acadêmica nos campos da administração pública comparativa e política comparada. Os fatores selecionados são:

- A estrutura básica do Estado, com referência à dispersão horizontal do poder (Pollitt e Bouckaert, 2004). Um sistema público é classificado tanto como coordenado quanto como fragmentado.

- A natureza do governo executivo, ou seja, as convenções de governança que configuram a forma como um governo funciona. Os sistemas são classificados como majoritários ou consensuais (LIJPHART, 1999).
- A cultura administrativa - Rechtsstaat ou interesse público (Pierre, 1995). No primeiro tipo, a lei está no cerne das relações entre o cidadão e o Estado, e o cidadão é principalmente um sujeito de direitos e deveres; em sistemas de interesse público, a lei está em segundo plano e o cidadão é principalmente considerado como um cliente.

- O status e prestígio associados ao trabalho para os diferentes níveis de governo.

O status pode ser superior no nível central do governo, maior no nível local ou similar nos diferentes níveis. Um legado da tradição administrativa napoleônica na Itália e Espanha é, em termos gerais, um maior status associado com o trabalho para o governo central. No Reino Unido, pode-se argumentar que o status é superior no nível 
central também, mas por um motivo diferente: o poder é tradicionalmente centralizado em Londres (um fator funcional e não uma característica cultural).

- A politização (presente versus ausente) de cargos gerenciais de nível elevado.

- A origem geográfica dos burocratas (Gualmini, 2003), sejam eles de áreas que apoiam ou são contra a devolução ou áreas "homogêneas".

- A orientação geral da gestão de recursos humanos no serviço civil. Uma das principais distinções dos sistemas é entre "orientado para a execução" versus o mais tradicional, "orientado para o cumprimento". Esse fator é determinado pelas regras da promoção dos funcionários civis e os sistemas efetivamente utilizados para avaliar o desempenho.

- A natureza da auditoria do setor público. Existem três etapas na reforma da auditoria pública (Pollitt e Bouckaert, 2004): auditoria de conformidade; auditoria de conformidade com alguns elementos de avaliação de desempenho; auditoria de conformidade e desempenho.

- A orientação geral de sistemas de gestão em organizações-chave envolvidas na devolução: "em direção à conformidade" ou "em direção ao desempenho".

- A capacidade de gestão nas organizações estratégicas em todo o país - "diferenciadas" (disparidades regionais na capacidade de gestão de administrações públicas) ou "homogêneas" (disparidades limitadas).

\section{Visão geral da devolução regional}

\section{Itália}

Regiões foram estabelecidas na Itália como resultado da Constituição democrática de 1948. No entanto, a chamada "primeira onda" de devolução começou somente na década de 1970 e resultou na implantação de regulamentações regionais ordinárias. Poucas funções e recursos foram transferidos para o governo regional, desvirtuando o projeto constitucional (BALDI, 2003). Regiões foram consolidadas em 1975 e em 1977, na seqüência da nova legislação que constitui poderes dos governos regionais e funções mais coerentes com a Constituição de 1948 (Gourevitch, 1978; Putnam, 1993).

Depois de muitos anos de negociações sobre a reforma, a "terceira devolução" (a segunda foi principalmente setorial) foi iniciada em 1997. O fato alterou significativamente a distribuição de funções administrativas entre os diferentes níveis de governo, mas não afetou a Constituição. Duas intervenções subseqüentes de reformas "federalismo fiscal" e uma reforma "federal" da Constituição - foram promulgadas.

\section{Espanha}

Ao longo das três décadas após a queda do regime franquista, a Espanha passou de um sistema centralizado para um de quasefederação, um "Estado regional" (ver Agranoff, 1996; Agranoff e Ramos, 1997; Alba, 1997; Moreno, 2001, 2002; Torres e PINA, 2004). O processo de devolução das camadas regionais do governo iniciou-se em 1978 com a criação da constituição democrática. A Constituição não determinou a distribuição territorial de poder e competências, mas permitiu um "processo aberto" com base numa devolução assimétrica, dependendo da vontade política das comunidades locais. Entre 1979 e 1983, 17 comunidades autônomas foram criadas e sete delas obtiveram um maior grau de autogoverno (em educação e assistência médica). Em 1980, os princípios do sistema financeiro foram criados para os 15 'regimes 


\section{Tabela 1: Devolução e sistemas político-administrativos: Itália, Espanha e Reino Unido}

\begin{tabular}{|c|c|c|c|}
\hline $\begin{array}{l}\text { Fatores } \\
\text { Sistema político-admi- } \\
\text { nistrativo e políticas } \\
\text { públicas de adminis- } \\
\text { tração pública }\end{array}$ & Itália & Espanha & Reino Unido \\
\hline $\begin{array}{l}\text { Estrutura básica do Estado } \\
\text { (coordenação horizontal do } \\
\text { governo central) }\end{array}$ & Fragmentada & Coordenada & Coordenada \\
\hline $\begin{array}{l}\text { Natureza do governo exe- } \\
\text { cutivo }\end{array}$ & $\begin{array}{l}\text { Consensual (em tran- } \\
\text { sição para majoritárias } \\
\text { a partir de 1993) }\end{array}$ & Majoritária & Majoritária \\
\hline Cultura Administrativa & Rechtsstaat & Rechtsstaat & Interesse público \\
\hline $\begin{array}{l}\text { Status social e prestígio no } \\
\text { serviço público }\end{array}$ & $\begin{array}{l}\text { Superior no nível } \\
\text { central }\end{array}$ & $\begin{array}{l}\text { Superior no nível } \\
\text { central }\end{array}$ & $\begin{array}{l}\text { Superior no nível } \\
\text { central }\end{array}$ \\
\hline $\begin{array}{l}\text { Politização das posições de } \\
\text { alto nível gerencial }\end{array}$ & Politizadas & Politizadas & Não-politizadas \\
\hline $\begin{array}{l}\text { Orientação geral da Gestão } \\
\text { de RH no serviço público }\end{array}$ & $\begin{array}{l}\text { Foco no cumprimento } \\
\text { das diretrizes }\end{array}$ & $\begin{array}{l}\text { Foco no cumprimento } \\
\text { das diretrizes }\end{array}$ & $\begin{array}{l}\text { Foco no } \\
\text { desempenho }\end{array}$ \\
\hline $\begin{array}{l}\text { Proveniência geográfica } \\
\text { dos burocratas }\end{array}$ & $\begin{array}{l}\text { Principalmente das } \\
\text { áreas com resistências } \\
\text { à devolução }\end{array}$ & Homogêneos & Homogêneos \\
\hline $\begin{array}{l}\text { Natureza da auditoria do } \\
\text { setor público }\end{array}$ & $\begin{array}{l}\text { Auditoria de confor- } \\
\text { midade com alguns } \\
\text { elementos da avalia- } \\
\text { ção do desempenho }\end{array}$ & $\begin{array}{l}\text { Auditoria de confor- } \\
\text { midade com alguns } \\
\text { elementos da avalia- } \\
\text { ção do desempenho }\end{array}$ & $\begin{array}{l}\text { Auditoria de } \\
\text { conformidade e } \\
\text { de desempenho }\end{array}$ \\
\hline $\begin{array}{l}\text { Orientação geral do sistema } \\
\text { gerencial em organizações- } \\
\text { chave }\end{array}$ & $\begin{array}{l}\text { No sentido da } \\
\text { conformidade }\end{array}$ & $\begin{array}{l}\text { No sentido da } \\
\text { conformidade }\end{array}$ & $\begin{array}{l}\text { No sentido da } \\
\text { conformidade }\end{array}$ \\
\hline $\begin{array}{l}\text { Capacidade gerencial de } \\
\text { organizações-chave diferen- } \\
\text { ciadas em todo o país }\end{array}$ & Diferenciadas & Diferenciadas & Não relevante \\
\hline \multicolumn{4}{|l|}{$\begin{array}{l}\text { Dinâmica e os efeitos } \\
\text { da devolução }\end{array}$} \\
\hline $\begin{array}{l}\text { Grau de intensidade } \\
\text { da devolução }\end{array}$ & Baixa & Relativamente alta & Alta \\
\hline Participação e accountability & $\begin{array}{l}\text { Não aumentou após } \\
\text { a devolução }\end{array}$ & $\begin{array}{l}\text { Não aumentou após } \\
\text { a devolução }\end{array}$ & $\begin{array}{l}\text { Aumentou após } \\
\text { a devolução }\end{array}$ \\
\hline
\end{tabular}

comuns' das Comunidades Autônomas. Até o início da década de 1990, o sistema de financiamento manteve-se bastante centralizado. As exceções foram dois governos regionais, o País Basco e Navarra, que coletavam suas próprias taxas de imposto de renda pessoal, de empresas e outros e, em seguida, transferiam certa quantia para o Estado para compensar as despesas gerais espanholas e para cobrir o custo dos serviços administrativos e dos órgãos geridos pelo Estado situados nessas regiões. 
Uma segunda onda de devolução ocorreu em 1992, através de um pacto político entre os dois maiores partidos nacionais, com o objetivo de alargar e acelerar a autonomia das regiões com menor grau de autogoverno. Após um acordo do Conselho de Política Fiscal e Financeira (1993), as comunidades do regime de financiamento comum recebem $15 \%$ do total do imposto de renda de pessoa física arrecadado no seu território. Em 1996, um novo acordo multipartidário fortaleceu o governo regional: a percentagem da renda pessoal que poderia reter foi aumentada para $30 \%$. O financiamento público foi modificado ainda mais em 2001, fortalecendo a autonomia regional. Até o momento de elaboração deste artigo, algumas disparidades no grau de autonomia das regiões ainda são presentes.

\section{Reino Unido - Escócia}

A devolução do poder à Escócia seguiu a vitória do Partido Trabalhista nas eleições gerais de 1997. O referendo sobre o assunto foi realizado naquele ano e o povo escocês votou em maioria pela devolução. O Ato da Escócia de 1998 estabeleceu o Executivo e o Parlamento daquele país. Eleições para o Parlamento escocês foram realizadas em 1999.

\section{Discussão}

Um primeiro fator que afeta a devolução é o grau de coordenação dentro do governo central. Essa variável é difícil de ser medida com precisão e não se apóia em disposições legais. No entanto, é evidente que a Itália é o país que apresenta uma estrutura mais fragmentada dentro do governo central, causada principalmente pela instabilidade do sistema político. Esse é um dos fatores que tornou a devolução na Itália menos intensa. O governo central forte do Reino Unido denotava que a devolução na Escócia poderia avançar rapidamente.

Um segundo fator de influência é a natureza do governo executivo. A implantação da devolução foi mais intensa principalmente onde o governo executivo é quase absolutamente majoritário. Esse argumento não é novo (e tem sido questionado - ver, por exemplo, Yesilkagit e De Vries,

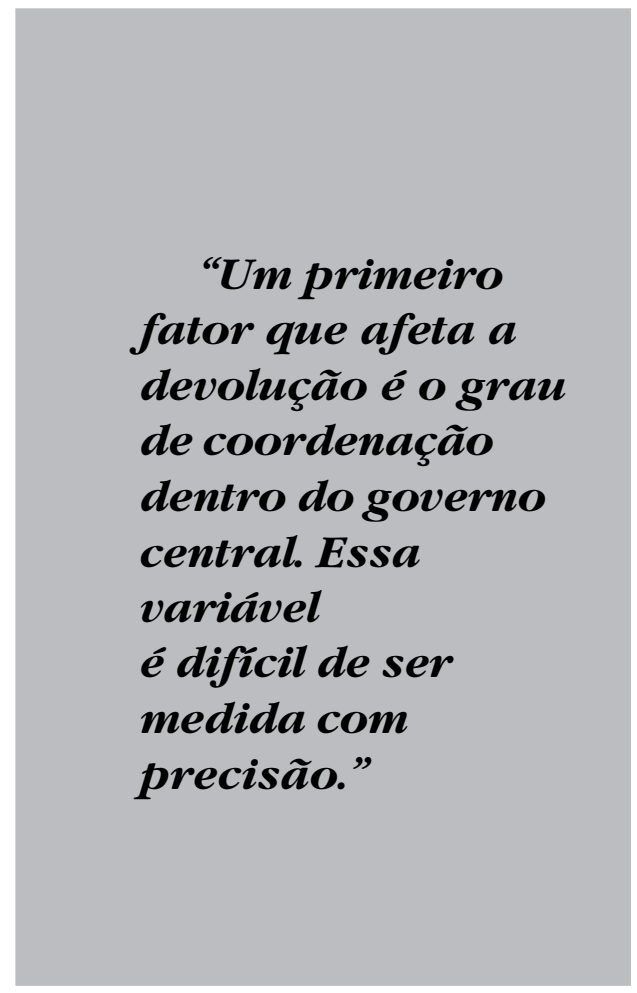

2004), mas os casos apresentados aumentam a credibilidade dele.

A cultura administrativa é um terceiro fator que influencia a intensidade da devolução. Isso ocorre porque a centralidade do direito administrativo pode levar a uma introdução "formalista" das reformas. Reforma pode ser considerada mais voltada a mudanças de leis do que da forma como as organizações públicas funcionam (sobre 
a influência do paradigma cultural do "direito administrativo" nas reformas da Itália, ver Capano, 2003). Além disso, a implantação das reformas nos países com base no direito administrativo exige legislação secundária a ser promulgada como uma etapa preliminar. No caso italiano, por exemplo, após a lei da reforma de 1997, quatro atos adicionais tiveram de ser passados para a regulação detalhada dos setores relevantes de políticas públicas. Cada governo regional teve que aprovar leis do seu nível para cada setor. Esse processo levou muitos anos.

Em quarto lugar, a maneira como altos funcionários civis são nomeados não é relevante, de uma maneira clara e direta, enquanto a orientação da gestão de recursos humanos no serviço civil é. A devolução tem sido mais intensa no Reino Unido, onde a orientação é no sentido de desempenho, mesmo que os burocratas não sejam nomeados politicamente (outros fatores fora do foco deste artigo, como a continuidade dos governos eleitos, são influentes também).

Um quinto argumento diz respeito à influência das condições do contexto sobre a redistribuição de pessoal, uma demanda crucial para o funcionamento eficaz (para ter a competência onde é necessário) e eficiente (para evitar excessivas duplicações) de um sistema não concentrado, especialmente se as tarefas de trabalho intensivo são descentralizadas. Foi argumentado que nos países napoleônicos os custos com pessoal a ser realocado em níveis mais baixos de governo excedem os benefícios (ONGARO, 2006). Custos podem ser resumidos em uma perda de status e prestígio associados ao trabalho para níveis mais baixos de governo e, pelo menos para os governos locais, com contrato de trabalho menos favorável.

Normas na área de pessoal permitem maior flexibilidade na realocação de funcionários no Reino Unido em comparação à Itália ou à Espanha. Consensualmente, o serviço público italiano "sob o domínio dos sindicatos" fornece meios mais fortes para funcionários resistirem a realinhamentos do que no serviço público britânico "pós-Thatcher". Uma interpretação mais completa das experiências específicas analisadas deve incluir considerações sobre o pacote de reformas (a opção de manter um serviço público unitário provavelmente tornou a implantação de instituições escocesas um processo mais ameno). Além disso, a preexistência de um gabinete escocês com organização de recursos humanos bem consolidados contribui para explicar a dinâmica da devolução. Essas escolhas políticas, aplicadas num contexto comparativamente mais favorável, fornecem novos elementos para a explicação sobre a rapidez e eficiência na implementação de mudanças drásticas na reforma no Reino Unido, comparadas à lentidão da Espanha e, especialmente, da Itália.

A composição geográfica do serviço público também pode influenciar. A burocracia italiana tem uma composição muito peculiar: a ampla maioria dos funcionários públicos da administração central vem do sul do país $(73 \%$ dos funcionários públicos e $93 \%$ dos altos burocratas, em 1995 ver CASSESE, 1999).

Este é um resultado da disparidade econômica entre o norte e o sul: tornarse um funcionário público sempre foi considerado pelos jovens sulistas uma boa oportunidade de conseguir um emprego. A "sulinização" da administração (SEPE et al., 2003) pode influenciar o processo de devolução de maneiras diversas:

- Muitos sulistas não são favoráveis à devolução, uma vez que pode aumentar 
disparidades regionais e enfraquecer as políticas redistributivas do Estado.

- A lacuna norte-sul não é apenas econômica, inclui também uma forte disparidade na capacidade administrativa (Putnam, 1993). Funcionários públicos do Sul no nível central poderiam ser céticos, por seu conhecimento direto sobre a capacidade dos governos regionais para executar as funções descentralizadas e sobre os benefícios gerais da reforma de devolução e, em última análise, se opor a ela.

Capacidade administrativa e organizacional nas organizações públicas estratégicas também pode influenciar a devolução. A capacidade organizacional mais forte nas organizações em que a autoridade é transferida pode criar condições favoráveis para uma implantação mais rápida da devolução. No Reino Unido havia tanto um modelo preexistente de desconcentração funcionando bem (o gabinete escocês) quanto um governo administrativo central forte. $\mathrm{Na}$ Itália e Espanha, onde tal capacidade gerencial é menor, a implantação da reforma tem sido menos intensa. No entanto, nos casos italiano e espanhol há diferenças interregionais por todo o território de ambos os países que fizeram a devolução mais rápida em algumas áreas - por exemplo, em algumas regiões do norte da Itália.

$\mathrm{O}$ argumento final refere-se aos fatores que afetam a participação e transparência após a devolução, que é maior no Reino Unido do que na Itália e na Espanha. A transparência no governo regional após a devolução parece ser influenciada pela capacidade organizacional das principais instituições envolvidas e pelo conteúdo de auditorias e processos de avaliação. $\mathrm{Na}$ Escócia, houve uma convergência entre as fortes habilidades gerenciais existentes no gabinete escocês e a orientação global para realizar auditoria. Assim, o governo escocês estava mais acostumado a práticas de participação e accountability (valor pelo dinheiro, auditoria de desempenho) e ao mesmo tempo "tinha que" adotá-las. Na Itália e Espanha, houve esforços para melhorar a accountability dos cidadãos (PezZAnI, 2005; TORRES e PINA, 2004), mas esse processo não foi movido pelas regiões, cuja capacidade administrativa era mais fraca e onde a auditoria focalizava na conformidade.

\section{Implicações para responsáveis por políticas públicas e gestores públicos}

Como os responsáveis por políticas públicas e gestores públicos podem melhor aplicar o conhecimento comparativo proporcionado pela dinâmica dos processos de devolução? Um modelo eficiente de extrair aprendizado - lesson-drawing, em inglês (DOLOWTTZ e MARSH, 2000) - tem sido descrito por Rose (2001). Extrair aprendizado refere-se à transferência voluntária de políticas públicas: os responsáveis por elas num determinado país decidem "livremente" procurar no exterior a fim de extrair aprendizados sobre como melhorar as políticas públicas ou reformar áreas do setor público. O modelo de Rose é baseado em 10 etapas. Ele é apresentado a seguir à luz de achados anteriores:

Etapa 1: Diagnosticando o problema. O primeiro passo aborda a questão da definição do que é o problema, a fim de identificar o que procurar. Embora nem todos os problemas requeiram a procura de soluções fora do país, no que diz respeito à devolução é pouco provável que os responsáveis por políticas públicas possam aprender como conduzir tais intervenções somente a partir de experiências anteriores na própria nação. 
Etapa 2: Decidindo onde procurar o aprendizado. Há uma série de fatores que podem afetar a decisão sobre de onde agregar as informações para aprender: proximidade cultural entre os países, compatibilidade ideológica entre os governos no poder, disponibilidade das evidências, interdependência. No entanto, esses fatores podem se tornar obstáculos (ou ao menos podem introduzir uma tendência) para a aprendizagem de políticas públicas, já que é principalmente o conhecimento sobre os resultados das reformas e as semelhanças e diferenças no contexto político-administrativo que devem orientar o processo de seleção sobre onde procurar por aprendizados.

Etapa 3: Investigando como funciona um programa. Estudo da reforma baseado tanto em estudo quanto em visitas ao local.

Etapa 4: Abstraindo um modelo de causa e efeito para exportação. Uma espécie de abordagem de "engenharia reversa" é necessária para compreender as variáveis-chave que explicam o funcionamento do sistema a ser copiado e seus prováveis efeitos.

Etapa 5: Criando um aprendizado. Aprendizados exigem boa habilidade em adaptar cuidadosamente um modelo abstrato de causa e efeito para as circunstâncias do país importador.

Etapa 6: Decidindo sobre a importação. Qualquer aprendizado a ser importado deve ser tanto viável (e para este momento o conhecimento comparativo fornecido aqui pode ser útil) quanto desejável (alinhada com as próprias ideias dos gestores de como o setor público deve funcionar).

Etapa 7: Lidando com os recursos e limitações. Eventuais restrições podem afetar especialmente as etapas 5 e 6.
Etapa 8: Lidando com o problema de contexto. Esta etapa, que se sobrepõe parcialmente às etapas quatro e cinco, é sobre como fazer com que a reforma a ser importada se encaixe no contexto de gestão político-administrativa e pública do país destinatário. Este artigo fornece aprendizados novos sobre essa etapa.

Etapa 9: Especulação limitadora por meio de avaliação em perspectiva. Uma avaliação ex ante do programa designado para a importação precisa ser realizada.

Etapa 10: Utilizando países estrangeiros como símbolos positivos ou negativos. $O$ consenso sobre a reforma tem que ser construído se for estabelecido no país destinatário. Sendo assim, uma forma comum de "marketing" de aprendizado extraído do estrangeiro é usar a percepção comum do que as pessoas de certa nação têm acerca de um país estrangeiro. Isso obviamente pode desorientar em alguns casos.

O esquema básico do modelo Rose pode ser analisado da seguinte forma: após a primeira etapa de diagnóstico do problema, um primeiro grupo de etapas (2 a 4) se refere à investigação relacionada ao contexto da experiência estrangeira, um segundo grupo (5 a 7) diz respeito à extração do aprendizado prático e à aplicabilidade no local almejado. Uma etapa além foca-se diretamente na questão das diferenças de contexto dos países, enquanto as etapas finais referem-se à criação de um consenso quanto à política a ser "importada” (9 e 10).

As etapas cruciais de extração de aprendizado exigem o tipo de conhecimento que os estudos comparativos fornecem sobre a influência dos fatores de contexto no processo de implantação de uma política pública. Assim, responsáveis por políticas públicas e gestores públicos no Reino Unido, 
preocupados com a questão da devolução de poderes de "regiões" inglesas e, possivelmente, preocupados com a alocação de pessoal, podem considerar sensivelmente a experiência escocesa em alguns aspectos "muito peculiares" (por causa da questão da identidade regional) e extrair aprendizado também das experiências selecionadas que se mostraram bem sucedidas, não obstante o contexto menos favorável (por exemplo, a devolução da agricultura na região italiana da Lombardia, especialmente o modo como foram realocados os funcionários, ver ONGARO, 2006, e ONGARO e Valotti, 2005). Responsáveis por políticas públicas e gestores nos países do Leste Europeu envolvidos em importantes processos de devolução podem examinar o rápido processo da Escócia e aprender como estabelecer uma nova instituição "regional" e descentralizar competências. Mas no que diz respeito à redistribuição de pessoal para as novas regiões, eles têm mais probabilidade de elaborar sistemas capazes de apoiar efetivamente o processo de implantação por meio da aprendizagem das experiências "de sucesso" que ocorreram nos países do Mediterrâneo, que se desdobraram em contextos (menos favoráveis) em muitos aspectos muito mais próximos de seus países. Gestores públicos em países do Mediterrâneo podem levar em consideração suas experiências comuns, mas também decidir procurar aprendizado nos países onde as reformas de devolução têm sido implantadas em ritmo muito mais rápido, como na Escócia. Para transferências úteis de aprendizados, responsáveis por políticas públicas precisam considerar cuidadosamente as diferenças profundas (bem como as semelhanças) entre os países. (Permissão para publicação obtida em maio de 2010. Versão final em junho de 2010.)

\section{Notas}

* Este trabalho é produto comum dos autores. Na redação final, Paolo Fedele preparou os trechos sobre "O modelo comparativo" e "Discussão" e o trecho sobre a Espanha. Edoardo Ongaro preparou os outros trechos.

1 Nesta versão em português, traduz-se devolution, do original em inglês, como devolução, por entendermos que o termo define com mais precisão o processo de descentralização que implica transferência do poder decisório da administração central para órgãos regionais, administrados por representantes eleitos.

\section{Referências bibliográficas}

Agranoff, R. Federal evolution in Spain. International Political Science Review, v. 17, no 4, p. 385-401, 1996.

Agranoff, R.; Ramos, J. A. Toward federal democracy in Spain: an examination of inter-governmental relations. Publius - The Journal of Federalism, v. 27, no 4, p. 1-38, 1997. 
AlBA, C. Modernizing Spanish public administration: old inertias and new challenges. In: Kickert, W. (Org.). Public Management and Administrative Reform in Western Europe. Cheltenham: Edward Elgar, 1997.

BALDI, B. Stato e territorio. Roma: Editori Laterza, 2003.

Barzelay, M. The New Public Management. Berkeley: University of California Press, 2001. Borgonovi, E. Principi e sistemi aziendaliper le amministrazioni pubbliche. Milão: Egea, 2005. CApano, G. Administrative traditions and policy change: when policy paradigms matter. The case of Italian administrative reform during the 1990s. Public Administration, v. 81, no 4, p. 781-801, 2003.

Cassese, S. Italy's senior civil service: an ossified world. In: Page, E. C. e Wright, V. (Org.). Bureaucratic Elites in Western European State. Oxford: Oxford University Press, 1999.

Dolowitz, D.; Marsh, D. Learning from abroad: the role of policy transfer in contemporary policy-making. Governance, v. 13, no 1, p. 5-24, 2000.

Ezzamel, M.; Hyndman, N. S.; Johensen, A.; Lapsley, I.; Pallott, J. Has devolution increased democratic accountability? Public Money \& Management, v. 24, no 3, p. 145-152, 2004.

Gualmini, E. L'amministrąione nelle democrąie contemporanee. Bari: Edizioni Laterza, 2003.

Gourevitch, P. Reforming the Napoleonic State: the creation of regional governments in France and Italy. In: TARrow, S. et al. (Org.). Territorial Politics in Industrial Nations. Nova Iorque: Praeger, 1978.

HeLler, W. B. Regional parties and national politics in Europe: Spain's Estado de las Autonomías. Comparative Political Studies, v. 35, nº 6, p. 657-685, 2002.

Keating, M. Rethinking the region. Culture, institutions and economic development in Catalonia and Galicia. European Urban and Regional Studies, v. 8, n 3, p. 217-234, 2001.

Kickert, W. J. M. Public Management and Administrative Reform in Western Europe. Cheltenham: Edward Elgar, 1997.

Kingdon, J. Agendas, Alternatives and Public Policies. Boston: Little Brown, 1994.

Lijphart, A. Patterns of Democracy: Governance Forms and Performance in 36 Countries. New Haven: Yale University Press, 1999.

Longo, F. Federalismo e decentramento: proposte economico-aziendali per le riforme. Milão: Egea, 2001.

Moreno, L. The Federalization of Spain. Londres: Frank Cass, 2001.

Moreno, L. Decentralization in Spain. Regional Studies, v. 36, no 4, p. 399-408, 2002.

Olsen, J. P.; Peters, B. G. Lessons from the Experience. Experiential Learning in Administrative Reforms in Eight Democracies. Oslo: Scandinavian University Press, 1996.

Ongaro, E.; ValotTi, G. La gestione del decentramento: governance e innovazione organizzativa nell'esperienza di regione ed enti locali in Lombardia. Milão: Giuffre, 2005.

Ongaro, E. The dynamics of devolution processes in legalistic countries: organizational change in the Italian public sector. Public Administration, v. 84, $\mathrm{n}^{\circ} 3$, p. 737-770, 2006. 
The Napoleonic administrative tradition: evolving features and influence on public management reform in France, Greece, Italy, Portugal, Spain. Trabalho apresentado no workshop Administrative tradition: inheritances and transplants in comparative perspective. Universidade de Hong Kong, 23 e 24 de junho de 2007.

Peters, B. G. Comparative Politics: Theory and Methods. Londres: Macmillan Press, 1998.

Pezzani, F (Ed). Logiche e strumenti di accountability per le amministrazioni pubbliche. Milão: EGEA, 2005.

Pierre, J. Bureaucracy in the Modern State. Cheltenham: Edward Elgar, 1995.

Polditt, C.; Birchall, J.; Putman, K. Decentralizing Public Service Management. Londres: Macmillan Press, 1998.

Pollitt, C.; Bouckaert, G. Public Management Reform. Oxford: Oxford University Press, 2004.

Putnam, R. Making Democracy Work. Princeton: Princeton University Press, 1993.

Rose, R. Ten steps in learning from abroad. Disponível em: www. futuregovernance.ac.uk.

Sepe, S.; Mazzone, L.; Portelli, I.; Vetritto, G. Lineamenti di storia dell'amministrazione Italiana. Roma: Carocci, 2003.

TORRes, L.; PINA, V. Reshaping public administration: the Spanish experience compared to the UK. Public Administration, v. 82, n. 2, p. 445-464, 2004.

Yesilkagit, K.; De Vries, J. Reform styles of political and administrative elites in majoritarian democracies: public management reform in New Zealand and the Netherlands. Public Administration, v. 82, n. 4, p. 951-974, 2004. 


\section{Resumo-Resumen-Abstract}

\section{Uma tendência comum, casas diferentes: devolução na Itália, Espanha e Reino Unido} Paolo Fedele e Edoardo Ongaro

A dinâmica do processo de implantação das reformas de devolução difere significativamente de país para país. A explicação reside em parte nas diferenças entre cada sistema político-administrativo e o status das reformas de administração pública. Fatores que afetam a devolução são analisados neste artigo. Implicações para os responsáveis por políticas públicas e gestores públicos, especialmente em relação à transferência de políticas de reformas de devolução, são discutidas.

Palavras-chave: Devolução, descentralização, administração pública

\section{Una tendencia común, casas diferentes: devolución Italia, España y Reino Unido \\ Paolo Fedele y Edoardo Ongaro}

La dinámica del proceso de implantación de las reformas de devolución significativamente distinta entre los países. La explicación está, en parte, en las diferencias entre cada sistema políticoadministrativo y el estatus de las reformas de administración pública. Factores que afectan a la devolución son analizados en este artículo. Implicaciones para los responsables de políticas públicas y gestores públicos, especialmente en lo que se refiere a la transferencia de políticas de reformas de devolución, son discutidas.

Palavras clave: Devolución, descentralización, administración pública

\section{A common trend, different houses: devolution in Italy, Spain and the UK \\ Paolo Fedele and Edoardo Ongaro}

The dynamics of the implementation process of devolution reforms differ significantly from country to country. Part of the explanation for this lies in the differences in the politico-administrative system and the status of public management reforms. Factors affecting devolution are examined in this article. Implications for policy-makers and public managers, especially regarding the policy transfer of devolution reforms, are discussed.

Keywords: Devolution, decentralization, public administration

\footnotetext{
Paolo Fedele

Pesquisador do Instituto de Administração Pública e Sistema de Saúde da Universidade Bocconi em Milão e professor assistente de administração pública na Escola de Administração SDA Bocconi.

Edoardo Ongaro

Professor de administração pública na Escola de Administração SDA Bocconi e de administração de organizações internacionais e supranacionais da Universidade Bocconi.
} 